\title{
Identification of the Risk Factors Associated with the Presence of HPV in Young University Students
}

\author{
Liliana S. Rodríguez*, Meryene Barrios and Claudia Pachón \\ Faculty of Health Sciences, Corporación Universitaria Antonio Jose de Sucre \\ CORPOSUCRE, Sincelejo, Colombia; liliana_rodriguez@corposucre.edu.co, \\ meryene_barrios@corposucre.edu.co,claudia_pachon@corposucre.edu.co
}

\begin{abstract}
Objective: To determine the main risk factors that favor the acquisition of the Human Papilloma Virus in university students. Methods/Statistical Analysis: This study used a cross-sectional descriptive research design to identify the risk factors associated with Human Papillomavirus (HPV) in university students. The study was carried out on 390 male and female students of Higher Education Institutions, of legal age and with an active sexual life. The data collected were analyzed with the Statistical Package for the Social Sciences (SPSS, Version 23.0). Findings: The study was applied to 390 students, of whom 205 are female and 185 male. From the study it can be identified that $15.4 \%$ of the cases presented a positive result in the presence of HPV, evidencing that the total number of people had a single marital status. Application/ Improvements: Based on this research, the risk factors associated with HPV could be identified in the university population. It is suggested that based on the results the educational institutions strengthen the information of future professionals and work directly or indirectly on the education of children and young people, from the curricular practices carried out in schools. Even in the same hospitals and health centers, try to approach them, regardless of the reason for seeking care.
\end{abstract}

Keywords: HPV, Risk Factor, University

\section{Introduction}

Genital infection by the Human Papilloma Virus (HPV) is the most prevalent sexually transmitted disease in the sexually active population and plays an important role in the genesis of preneoplastic lesions and invasive cervical cancer. In the latter, the cells grow and divide to produce more cells only when the body needs them ${ }^{1}$. This orderly process helps maintain division when new cells are not needed. These cells can form an additional tissue mass called tumor growth. Tumors can be classified as benign or malignant ${ }^{2}$.

This infection constitutes a serious public health problem, as evidenced by the World Health Organization (WHO) ${ }^{3}$. In addition, it is a problem that is exacerbated by generating high costs to the health system, limiting the timely practice of clinical tests that allow the detection of the disease. This situation occurs because funding for prevention and control programs is insufficient.

Public health entities, in underdeveloped countries, indicate that the most affected population is the one that lacks knowledge about the disease, and that this increases the mortality rate worldwide ${ }^{4}$. In addition, it is necessary to highlight that most people who do not have any knowledge about the virus, do not practice preventive attitudes against it, which considerably increases the pathological and harmful consequences in people who are exposed ${ }^{5}$. Likewise, the authors describe that young people do not have adequate knowledge of sexual contraceptive methods and sexually transmitted infections, so they are frequently exposed to the risk of unwanted pregnancy and sexually transmitted infections ${ }^{6}$.

In women, the risk of contracting HPV infection is mainly affected by sexual activity. The first intercourse, at

${ }^{*}$ Author for correspondence 
an early age, is a risk factor for HPV infection, since a cervix that has not developed has an immature epithelium, which can be more easily penetrated by the virus. Other factors that contribute to HPV infection, include having had the first birth at a young age and having been infected with HIV or other sexually transmitted infections (STIs), for example, by herpes virus, or Chlamydia trachomatis. In the case of men, the risk factors for HPV infection include having multiple sexual partners, having same-sex partners and not being circumcised.

The presence of other associated factors is necessary to produce the disease. Among these we have: inappropriate sexual behavior, since having many sexual partners is a risk factor for HPV infection; the early onset of sexual relations; tobacco use: women smokers have a higher risk of cervical cancer than non-smoking women, since research studies have shown that high concentrations of substances from tobacco have been found in cervical mucus (substance that lines the mucous membrane of the cervix). Also, the number of pregnancies, due to the hormonal changes that occur during pregnancy, because these favor the development of HPV infections; the depressed immune system; genetic factors or diseases such as Acquired Immune Deficiency Syndrome (AIDS); medicines; drug use, etc.

All the above, cause immunosuppression of the person, and predispose to the development of anogenital and cervical cancer in the presence of infection by Human Papilloma Virus. Scientific studies have estimated that women who use oral contraceptives for more than 5 years double the risk of cervical cancer. It is considered that a diet low in antioxidants, folic acid and vitamin C, favors the persistence of infection by Human Papilloma Virus, the evolution of lesions and cervical cancer ${ }^{1}$.

Colombia has an incidence, for HPV Human Papilloma Virus, adjusted to 36.8 new cases per 100,000 women, and is located within countries with high risk for the disease. With a prevalence of 14.8 per 100,000 , this continues to be the main cause of death from cancer among Colombian women, with no tendency to decrease, despite the fact that there is an early detection program for 20 years. High-risk oncogenic HPVs have been associated in $99.8 \%$ with the development of cervical cancer and $1 \%$ with cancer of the penis. Risk factors have been reported, mainly sexual behavior for the acquisition of HPV. The beginning of sexual relations at an early age, the number of sexual partners, among others, are the main risk factors for acquiring this infection. The high point is that sexually active people contract the infection shortly after the onset of sexual life. HPV is transmitted sexually, although it is not necessary to have a sexual relationship with penetration for transmission to occur. Direct contact with the skin of the genital area is a recognized mode of transmission ${ }^{3}$.

Due to the above, it is necessary to carry out this preliminary study in the Municipality of Sincelejo (Sucre), Colombia, to identify the risk factors associated with infection in university students, in order to implement prevention strategies, assigning responsibilities and changing habits about safe sex for the university population, one of the most vulnerable and most ignorant of these issues. And, thus, control the disease in the Institutions of Higher Education of the Municipality of Sincelejo.

\section{Materials and Methods}

Study Design: This study used a cross-sectional descriptive research design to identify the risk factors associated with Human Papilloma Virus (HPV) in university students.

Samples of Studies: The research was conducted in 2016, as a cross-sectional descriptive study. The study was carried out on 390 male and female students of Higher Education Institutions, of legal age and with an active sexual life. All the students were given a survey, after explaining the objective of the study. Likewise, in order to detect the presence of Human Papillomavirus (HPV) and be able to establish the risk factors associated with HPV infection, samples of cervical and penile body brushes, obtained from the patient, were included in the study of 205 women and 185 men. The collected data were analyzed by descriptive statistics, using the SPSS 23.0 software. The information collection method was a self-administered survey, where validation and reliability were carried out under the Cronbach's Delphi and Alpha Technique.

Data Analysis: The collected data were analyzed with the Statistical Package for the Social Sciences (SPSS, Version 23.0). Descriptive statistics were used to identify the risk factors associated with the HPV of the participants. A multivariate analysis was performed to determine the relationship between the associated risk factors and the positive presence of the virus in the participants.

Measurements: The variables that were detected for the identification of the associated risk factors in the 
participants that tested positive for HPV were: demographic data, sexual behavior, history of sexually transmitted diseases and healthy habits, in which there were selected marital status, socioeconomic stratum, sexually active, how many people different from your regular partner have you had sex?, alcohol consumption, smoker, and do you cleanse your genitals after sexual intercourse?

\section{Results}

The study was applied to 390 people, of whom 205 are female and 185, male. From the study it can be identified that $15.4 \%$ of the cases presented positive results in the presence of HPV, evidencing that the total number of people had single marital status, as shown in Table 1. When analyzing the Table, it is observed that, of the total of the positive cases ( 60 cases), $18 \%$ correspond to the masculine gender and $82 \%$ to the feminine gender, as shown in Figure 1.

The results of the survey applied to each of the participants are shown:

Socioeconomic Stratum: Regarding the socioeconomic stratum, it was found that in the case of female gender, $59.2 \%$ is from Stratum 1; $32.7 \%$ of Stratum 2; and the remaining $8.2 \%$ of Stratum 3. In the case of the male gender, it was evident that $54.5 \%$ is from Stratum 1; $36.4 \%$ of Stratum 2; and 9.1\%, of Stratum 3. It is observed that, of the total positive cases, $58.3 \%$ are from Stratum 1, as shown in Table 2.

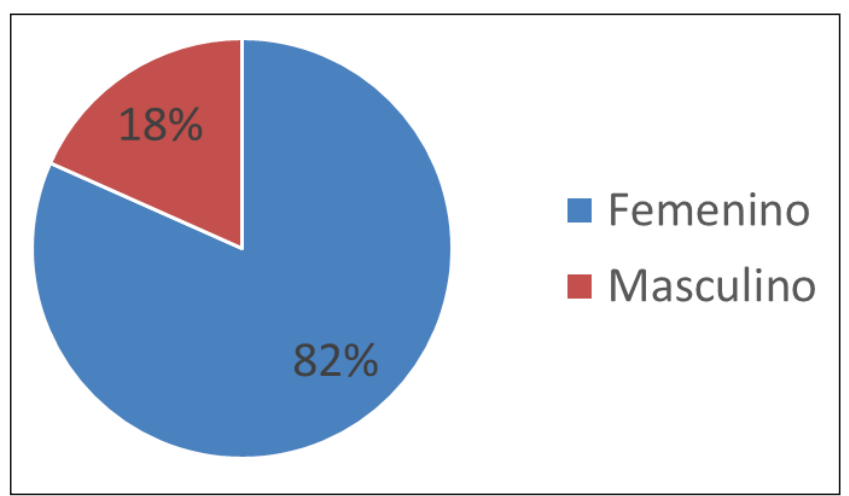

Figure 1. Distribution of positive cases by gender.

Sexually Active: Table 3 shows that $86.7 \%$ of the population with HPV presence, at which the tests were performed, are sexually active, and $13.3 \%$ are not. Additionally, it is observed that, in the feminine gender, $85.7 \%$ are sexually active; and in the masculine gender, $90.9 \%$ are.

Suffer or have suffered an STI: Regarding the question, do you suffer or have you suffered from a sexually transmitted disease?, it can be seen in Table 4 . that $95.0 \%$ said No. It can be analyzed that $9.1 \%$ of the male gender and $4.1 \%$ of the female gender said that they did have suffer an STD.

It is observed in Table 5 that $80.0 \%$ of the total male and female genders did not have sexual relations with any other person than their usual partner, but it is also observed that $27.3 \%$ and $18.2 \%$ of male participants had

Table 1. Civil status of the participants

\begin{tabular}{|l|c|c|c|c|c|c|}
\hline & \multicolumn{2}{|c|}{ Female } & \multicolumn{2}{c|}{ Male } & \multicolumn{2}{c|}{ Total } \\
\hline & Negative & Positive & Negative & Positive & Negative & Positive \\
\hline TOTAL & 156 & 49 & 174 & 11 & 330 & 60 \\
\hline Married & 4 & 0 & 8 & 0 & 12 & 0 \\
\hline Single & 151 & 49 & 148 & 11 & 299 & 60 \\
\hline Free Unión & 1 & 0 & 18 & 0 & 19 & 0 \\
\hline
\end{tabular}

Tabla 2. Socioeconomic stratum of the participants

\begin{tabular}{|l|c|c|c|c|c|c|}
\hline \multicolumn{1}{|c|}{ Category } & Female & $\%$ & Male & $\%$ & Total & $\%$ \\
\hline Stratum 1 & 29 & $59,2 \%$ & 6 & $54,5 \%$ & 35 & $58,3 \%$ \\
\hline Stratum 2 & 16 & $32,7 \%$ & 4 & $36,4 \%$ & 20 & $33,3 \%$ \\
\hline Stratum 3 & 4 & $8,2 \%$ & 1 & $9,1 \%$ & 5 & $8,3 \%$ \\
\hline Stratum 4 & 0 & $0,0 \%$ & 0 & $0,0 \%$ & 0 & $0,0 \%$ \\
\hline
\end{tabular}


Table 3. Sexually active

\begin{tabular}{|c|c|c|c|c|c|c|}
\hline Category & Female & $\%$ & Male & $\%$ & Total & $\%$ \\
\hline No & 7 & $14,3 \%$ & 1 & $9,1 \%$ & 8 & $13,3 \%$ \\
\hline Yes & 42 & $85,7 \%$ & 10 & $90,9 \%$ & 52 & $86,7 \%$ \\
\hline
\end{tabular}

Table 4. You have or have had an STI

\begin{tabular}{|c|c|c|c|c|c|c|}
\hline Category & Female & $\%$ & Male & $\%$ & Total & \% \\
\hline No & 47 & $95,9 \%$ & 10 & $90,9 \%$ & 57 & $95,0 \%$ \\
\hline Yes & 2 & $4,1 \%$ & 1 & $9,1 \%$ & 3 & $5,0 \%$ \\
\hline
\end{tabular}

Table 5. Amount of people other than the habitual couple with whom you have had sexual relationships

\begin{tabular}{|c|c|c|c|c|c|c|}
\hline Category & Female & $\%$ & Male & $\%$ & Total & $\%$ \\
\hline 0,00 & 45 & $91,8 \%$ & 3 & $27,3 \%$ & 48 & $80,0 \%$ \\
\hline 1,00 & 3 & $6,1 \%$ & 1 & $9,1 \%$ & 4 & $6,7 \%$ \\
\hline 2,00 & 1 & $2,0 \%$ & 2 & $18,2 \%$ & 3 & $5,0 \%$ \\
\hline 3,00 & 0 & $0,0 \%$ & 3 & $27,3 \%$ & 3 & $5,0 \%$ \\
\hline 4,00 & 0 & $0,0 \%$ & 0 & $0,0 \%$ & 0 & $0,0 \%$ \\
\hline 5,00 & 0 & $0,0 \%$ & 0 & $0,0 \%$ & 0 & $0,0 \%$ \\
\hline 6,00 & 0 & $0,0 \%$ & 2 & $18,2 \%$ & 2 & $3,3 \%$ \\
\hline
\end{tabular}

relationships with 3 to 6 people other than their usual partner, respectively.

Sexual Relations with Prostitutes: Regarding the question, Have you ever had sex with prostitutes?, it is observed that $18.2 \%$ of male participants stated that Yes, that they have had sex with prostitutes, as shown in Table 6.

Consumption of Alcoholic Beverages: With respect to Alcohol Consumption, participants stated, in $78.3 \%$, that they do consume it, highlighting that, in the male gender, $100 \%$ do so, as shown in Table 7.

Smoker: The Table 8 shows that $93.3 \%$ of the participants never smoked, and the remaining $6.7 \%$ did so at some point in their lives.

Cleansing of Genitals after Sexual Relationship: To the question of whether the person cleans their genitals after sexual intercourse, it is observed that $86.7 \%$ of the total

Table 6. Sexual relations with prostitutes

\begin{tabular}{|c|c|c|c|c|c|c|}
\hline Category & Female & $\%$ & Male & $\%$ & Total & \% \\
\hline NA & 49 & $100,0 \%$ & 0 & $0,0 \%$ & 49 & $91,7 \%$ \\
\hline No & 0 & $0,0 \%$ & 9 & $81,8 \%$ & $15,0 \%$ \\
\hline Yes & 0 & $0,0 \%$ & 2 & $18,2 \%$ & 2 & $3,3 \%$ \\
\hline
\end{tabular}

Table 7. Consumption of alcoholic beverages

\begin{tabular}{|c|c|c|c|c|c|c|}
\hline Category & Female & $\%$ & Male & $\%$ & Total & \% \\
\hline No & 13 & $26,5 \%$ & 0 & $0,0 \%$ & 13 & $21,7 \%$ \\
\hline Yes & 36 & $73,5 \%$ & 11 & $100,0 \%$ & 47 & $78,3 \%$ \\
\hline
\end{tabular}


Table 8. Smoker

\begin{tabular}{|l|c|c|c|c|c|c|}
\hline \multicolumn{1}{|c|}{ Category } & Female & $\%$ & Male & $\%$ & Total & \% \\
\hline Ex Smoker & 2 & $4,1 \%$ & 2 & $18,2 \%$ & $6,7 \%$ \\
\hline I currently smoke & 0 & $0,0 \%$ & 0 & $0,0 \%$ & 0 & $0,0 \%$ \\
\hline I have never smoked & 47 & $95,9 \%$ & 9 & $81,8 \%$ & 56 & $93,3 \%$ \\
\hline
\end{tabular}

Table 9. Cleansing of genitals after sexual relationships

\begin{tabular}{|c|c|c|c|c|c|c|}
\hline Category & Female & $\%$ & Male & $\%$ & Total & $\%$ \\
\hline Never & 1 & $2,0 \%$ & 0 & $0,0 \%$ & 1 & $1,7 \%$ \\
\hline Occasionally & 7 & $14,3 \%$ & 0 & $0,0 \%$ & 7 & $11,7 \%$ \\
\hline Always & 41 & $83,7 \%$ & 11 & $100,0 \%$ & 52 & $86,7 \%$ \\
\hline
\end{tabular}

population surveyed said that they always do, as shown in Table 9. The remaining participants of the sample They stated that they never do it or do it occasionally.

\section{Discussion}

In this research it was shown that $58.3 \%$ of the population with HPV presence is from Social Stratum 1 (Higher Poverty Index). This situation shows that the appearance of cervical cancer is more likely to occur in this population, indicating that it is closely related to poverty, in which inequities in health become palpable ${ }^{7}$. Additionally, it is appreciated that $86.7 \%$ of university students are sexually active, so it is considered a risk factor, not because they are sexually active but because, according to sociocultural conditions, they do not have a preparation and orientation for responsible behavior of their sexuality ${ }^{8}$.

On the other hand, it is highlighted that $5.0 \%$ of the population has suffered a Sexually Transmitted Disease (STD). Although the percentage is not statistically significant, it can be stated that, if there is no culture of responsibility in sexual life, there may be an increase in Sexually Transmitted Diseases among university students. Sexually Transmitted Infections (STI) are now a global epidemic. It is estimated that there are about 250 million new cases, annually, of which about 50 million correspond to the Americas? ${ }^{9}$. The most frequent of these are those caused by HPV, bacterial vaginosis, genital herpes simple, Chlamydia infections, gonococcia, syphilis and HIV/AIDS. All can cause serious consequences to reproductive health.

The data obtained in this research with respect to the number of sexual partners, which was $72.8 \%$ of university students, who had between 1 and 6 sexual partners, correspond to what was proposed by other authors, who point out that it is an indicator of risk to acquire STIs, and that has been referred in a constant way in several studies. Likewise, it is reported that the risk of HPV infection was associated with the increase in the number of sexual partners ${ }^{10}$. These results are also similar to those obtained in the study conducted in the city of Querétaro, in the state of Querétaro, in Mexico, where the results show a high percentage of sexually active adolescents, who have had between one and two couples (34\%) and 16.5\% with more than 3 sexual partners, which puts them at potential risk of carrying the HPV or other STI in the future, or of developing some type of cancer according to gender ${ }^{11,12}$.

The researchers of this study recognize the importance and need to continue investigating in a more specific and detailed way regarding the contagion by HPV, in order to continue impacting the entire population on the knowledge and risk factors that are associated to sexually transmitted diseases, as reported by other authors, who recognize the need to conduct quantitative and qualitative research, where cultural values of the feminine and masculine, meanings of sexuality and the body, organization of the health system, social support networks and, of course, aspects related to family, employment and others ${ }^{11}$. 


\section{Conclusions}

With the results of this research, the need to reinforce information on risk factors is established. From clarifying with the university students that the early onset of sexual life is one of the predisposing factors and that having relationships with multiple couples favors the risk of acquiring the infection or presenting future consequences. The aforementioned, shows a worrisome situation, as could be seen: the university students who participated in this study have begun their sexual life and some of them, despite their maturity, have had experiences with more than one couple, without having the elements that help them prevent or avoid risky behaviors.

In this sense, it is suggested, based on these results, that educational institutions strengthen the information of future professionals and work directly or indirectly in the education of children and young people, from the curricular practices that are carried out in the schools Even in the same hospitals and health centers, try to approach them, regardless of the reason for seeking care.

Finally, and to take into account the importance of this research, reference is made to what has been expressed and supported by authors such as, who state that "HPV is classified as one of the most frequent sexually transmitted diseases worldwide".

\section{References}

1. Rocha RMR, Juárez JME, Ruiz JMM, Ramírez BXG, Gaytán SMR, Contreras VP. Identification of risk factors to acquire the human papillomavirus in sexual-server. Revista Cubana de Obstetricia y Ginecología. 2012; 38(2):244-55.

2. Vidya R, Nasira GM. Prediction of cervical cancer using hybrid induction technique: A solution for human hereditary disease patterns. Indian Journal of Science and Technology. 2016; 9(30):1-10. Crossref.
3. Organización Mundial de la Salud. Informe mundial sobre la discapacidad; 2011. p. 1-27.

4. Rodríguez LS, Gonzalez J, Barrios $\mathrm{M}$, Pachon C. Physiotherapeutic intervention in a patient with Spinal Cord Injury (SCI). Indian Journal of Science and Technology. 2017; 10(32):1-7. Crossref.

5. Valdez C, Evelyn G. Relación entre el nivel de conocimiento y las actitudes preventivas sobre la infección por Virus del Papiloma Humano en usuarias del centro de salud "Chancas de Andahuaylas" de Santa Anita, primer semestre del; 2015. p. 1-59.

6. Kim M, Choi J-H. A study on sexual behavior, sexual knowledge, and sexual assertiveness among Korean College Students. Indian Journal of Science and Technology. 2016; 9(29):1-8. Crossref.

7. Palacio-Mejía LS, Rangel-Gómez G, Hernández-Avila M, Lazcano-Ponce E. Cervical cancer, a disease of poverty: Mortality differences between urban and rural areas in Mexico. Salud Pública de México. 2003; 45:15-25. Crossref.

8. Mayra B-RG, Abisai M-S, Inés T-Q, Concepción J, Yarely L-M. Conocimiento y prácticas de prevención sobre el Virus del Papiloma Humano (VPH) en universitarios de la Sierra Sur, Oaxaca. Anales de la Facultad de Medicina. 2015; 76(4):369-76.

9. Irene JM, Marisel CD, Reina PM. Infection caused by human papiloma Virus. Frequency in our environment. Revista Archivo Médico de Camagüey. 2000; 4(3):1025.

10. Rodríguez González D, Pérez Pi-ero J, Sarduy Nápoles M. Infection by the human papillomavirus and associated factors in middle-aged women. Revista Cubana de Obstetricia y Ginecología. 2014; 40(2):218-32.

11. Contreras-González R, Magaly-Santana A, Jiménez-Torres E, Gallegos-Torres R, Xeque-Morales Á, Palomé-Vega G. Nivel de conocimientos en adolescentes sobre el virus del papiloma humano. Enfermería Universitaria. 2017; 14(2):104-10. Crossref.

12. Bosch FX, Lorincz A, Mu-oz N, Meijer CJLM, Shah KV. The causal relation between human papillomavirus and cervical cancer. Journal of Clinical Pathology. 2002; 55(4):244-65. Crossref. PMid:11919208. PMCid:PMC1769629 